\title{
Treatment of induction in resectable NSCLC with chemotherapy, followed by surgery and erlotinib
}

\author{
Fernando Franco, Mariano Provencio \\ Department of Medical Oncology, Puerta de Hierro Hospital, Madrid, Spain \\ Correspondence to: Mariano Provencio. Department of Medical Oncology, Puerta de Hierro Hospital, Madrid, Spain. Email: mprovenciop@gmail.com. \\ Comment on: Cascone T, Gold KA, Swisher SG, et al. Induction Cisplatin Docetaxel Followed by Surgery and Erlotinib in Non-Small Cell Lung \\ Cancer. Ann Thorac Surg 2018;105:418-24.
}

Submitted Aug 31, 2018. Accepted for publication Sep 12, 2018.

doi: $10.21037 / \mathrm{atm} .2018 .09 .38$

View this article at: http://dx.doi.org/10.21037/atm.2018.09.38

We have carefully read the article by Dr. Cascone et al. in which they report the results of a phase 2 study evaluating the role of the induction therapy with cisplatin plus docetaxel, followed by a surgery and erlotinib in patients with resectable non-small cell lung cancer (NSCLC). This study has been registered as NCT00254384 and the data presented in the aforementioned article correspond to longterm efficacy results (1).

We know that the limited stages of NSCLC comprise a miscellany of diseases with a diverse biological behaviour and with wide differences in terms of survival according to the stage of the disease at the moment of diagnosis. Several studies have shown that adjuvant chemotherapy (CT) provides a survival benefit in patients with completely resected NSCLC (2-6). Furthermore, the LACE metaanalysis analysing data from 5 studies confirms the improvement in survival in patients treated with platinumbased CT. This meta-analysis, which includes more than 4,500 patients, with a median follow-up of 5.2 years, shows a decrease in the risk of death of $5.4 \%$ at 5 years in patients treated with CT compared to those who did not receive it (HR 0.89). However, this benefit is statistically significant only in the subgroup of patients with stage II and IIIA of the disease (HR 0.83) (7).

In the case of induction therapy, there is not as much data as in the adjuvant treatment in these patients. However, comparative analyses seem to indicate that there are no differences in overall survival (OS), although it can improve the results of surgery and allow less extensive resections (8-10).

In the Dr. Cascone's study a total of 47 patients were included and started the CT induction treatment. Only 13 of them had histological confirmation of mediastinal lymph node involvement. The majority of the patients had good tolerance to the treatment and less than $15 \%$ of them required a reduction of the CT dose. Seventy-nine percent of the patients treated with neoadjuvant CT were operated and the most performed intervention was lobectomy (66\%), followed by pneumonectomy (9\%). However, only $3 \%$ of the complete pathological responses (pCR) and 19\% of the major pathological responses (MPR) were conformed ( 3 cases in patients with stage I, 3 in stage III and only one case in stage II). Only $57 \%$ of patients started the adjuvant treatment with erlotinib and only 12 of them managed to complete the 12 -month adjuvant period. The OS at 5 years was $51.9 \%$ for stage I patients, $55.5 \%$ for stage II and $21.1 \%$ for stage III. The relapse rate throughout the follow-up was $57 \%$.

The analysis of the results in terms of survival does not provide any benefit with respect to historical controls, compared to the patients treated exclusively with induction CT (based on platinum). On the other hand, the addition of the adjuvant erlotinib to the treatment not only does not provide any survival benefits, but also carries the risk of compromising the quality of life due to some associated adverse events. These data are consistent with the results of the RADIANT study that included 973 patients (11). This study evaluated the role of the adjuvant treatment with erlotinib without finding any benefit in survival in these patients. In addition, the pathological analysis of the surgically treated patients does not show any differences in the pCR or MPR rates with respect to those, described in 
the previous series (12). Even the MPR, a survival surrogate in patients with NSCLC treated with neoadjuvant CT, is lower in this study (19\%) compared to previous studies in which it was around $22 \%$ (12).

One of the aspects to consider while analysing the results of this study, is that the recruitment was done a decade ago and therefore the application of the data is limited. One of the reasons is that in recent years the impact of immunotherapy (IO) has been demonstrated in patients with advanced NSCLC both in the first-line of treatment and in later lines (13-16). These treatments, used in monotherapy or in combination with other immunotherapeutic drugs or CT, have shown significant response rates, as well as a benefit in survival and quality of life. However, if IO is effective in patients with metastatic disease, it is likely that there is a potential activity which improves the results of induction treatments in patients with potentially resectable disease. Actually, there are currently 3 clinical trials evaluating the role of IO in this group of patients with NSCLC.

The first study, published by Forde PM in May 2018, evaluates the use of neoadjuvant nivolumab at a dose of $3 \mathrm{mg} / \mathrm{kg}$ every 2 weeks in patients with NSCLC stages IIIIA (NCT02259621) (17). From all 21 patients included, 20 were subsequently operated. The MPR rate was $45 \%$ and the tolerance to the treatment was excellent. Another of the neoadjuvant studies in NSCLC stages I-IIIA with IO is the CheckMate816 which is the ongoing phase 3 trial. This study includes 3 treatment arms: nivolumab plus ipilimumab vs nivolumab plus CT vs. CT alone. And finally the NADIM study of the Spanish Lung Cancer Group (SLCG), which is an exploratory phase 2 study, evaluating the efficacy of the combination of CT + IO with carboplatin plus paclitaxel plus nivolumab (18). This study is designed for patients with resectable NSCLC (stage IIIA) and has already closed its recruitment. The partial data, presented at ASCO 2018 with a total of 43 patients recruited and 22 of them already operated, show an overall response rate of $78 \%$ (pCR: $60 \%+$ MPR: $18 \%$ ). Therefore, although the results of induction studies in potentially resectable NSCLC whose protocols include IO are promising, they are still immature but probably in a short period of time they will became a new standard of treatment.

\section{Acknowledgements}

None.

\section{Footnote}

Conflicts of Interest: The authors have no conflicts of interest to declare.

\section{References}

1. Cascone T, Gold KA, Swisher SG, et al. Induction Cisplatin Docetaxel Followed by Surgery and Erlotinib in Non-Small Cell Lung Cancer. Ann Thorac Surg 2018;105:418-24.

2. Arriagada R, Bergman B, Dunant A, et al. Cisplatinbased adjuvant chemotherapy in patients with completely resected non-small-cell lung cancer. $\mathrm{N}$ Engl J Med 2004;350:351-60.

3. Scagliotti GV, Fossati R, Torri V, et al. Randomized study of adjuvant chemotherapy for completely resected stage I, II, or IIIA non-small-cell Lung cancer. J Natl Cancer Inst 2003;95:1453-61.

4. Douillard JY, Rosell R, De Lena M, et al. Adjuvant vinorelbine plus cisplatin versus observation in patients with completely resected stage IB-IIIA non-small-cell lung cancer (Adjuvant Navelbine International Trialist Association [ANITA]): a randomised controlled trial. Lancet Oncol 2006;7:719-27.

5. Winton T, Livingston R, Johnson D, et al. Vinorelbine plus cisplatin vs. observation in resected non-small-cell lung cancer. N Engl J Med 2005;352:2589-97.

6. Strauss GM, Herndon JE 2nd, Maddaus MA, et al. Adjuvant paclitaxel plus carboplatin compared with observation in stage IB non-small-cell lung cancer: CALGB 9633 with the Cancer and Leukemia Group B, Radiation Therapy Oncology Group, and North Central Cancer Treatment Group Study Groups. J Clin Oncol 2008;26:5043-51.

7. Pignon JP, Tribodet H, Scagliotti GV, et al. Lung adjuvant cisplatin evaluation: a pooled analysis by the LACE Collaborative Group. J Clin Oncol 2008;26:3552-9.

8. Lim E, Harris G, Patel A et al. Preoperative versus postoperative chemotherapy in patients with resectable non-small cell lung cancer: systematic review and indirect comparison meta-analysis of randomized trials. J Thorac Oncol 2009;4:1380-8.

9. NSCLC Meta-analysis Collaborative Group. Preoperative chemotherapy for non-small-cell lung cancer: a systematic review and metaanalysis of individual participant data. Lancet 2014;383:1561-71.

10. Gilligan D, Nicolson M, Smith I, et al. Preoperative 
chemotherapy in patients with resectable non-small cell lung cancer: results of the MRC LU22/NVALT 2/ EORTC 08012 multicentre randomised trial and update of systematic review. Lancet 2007;369:1929-37.

11. Kelly K, Altorki NK, Eberhardt WE, et al. Adjuvant Erlotinib Versus Placebo in Patients With Stage IBIIIA Non-Small-Cell Lung Cancer (RADIANT): A Randomized, Double-Blind, Phase III Trial. J Clin Oncol 2015;33:4007-14.

12. Hellmann MD, Chaft JE, William WN Jr, et al. Pathological response after neoadjuvant chemotherapy in resectable non-small-cell lung cancers: proposal for the use of major pathological response as a surrogate endpoint. Lancet Oncol 2014;15:e42-50.

13. Brahmer J, Reckamp KL, Baas P, et al. Nivolumab versus Docetaxel in Advanced Squamous-Cell Non-Small-Cell Lung Cancer. N Engl J Med 2015;373:123-35.

14. Reck M, Rodríguez-Abreu D, Robinson AG, et al. Pembrolizumab versus Chemotherapy for PD-L1Positive Non-Small-Cell Lung Cancer. N Engl J Med

Cite this article as: Franco F, Provencio M. Treatment of induction in resectable NSCLC with chemotherapy, followed by surgery and erlotinib. Ann Transl Med 2018;6(Suppl 1):S31. doi: 10.21037/atm.2018.09.38
2016;375:1823-33.

15. Rittmeyer A, Barlesi F, Waterkamp D, et al. Atezolizumab versus docetaxel in patients with previously treated non-small-cell lung cancer (OAK): a phase 3, openlabel, multicentre randomised controlled trial. Lancet 2017;389:255-65.

16. Langer CJ, Gadgeel SM, Borghaei H, et al. Carboplatin and pemetrexed with or without pembrolizumab for advanced, non-squamous non-small-cell lung cancer: a randomised, phase 2 cohort of the open-label KEYNOTE-021 study. Lancet Oncol 2016;17:1497-508.

17. Forde PM, Chaft JE, Smith KN, et al. Neoadjuvant PD1 Blockade in Resectable Lung Cancer. N Engl J Med 2018;378:1976-86.

18. Provencio M, Nadal E, Cobo M, et al. Neo-Adjuvan Chemo/Immunotherapy for the treatment of stages IIIA resectable Non-Small Cell Lumg Cancer (NSCLC): A phase II multicenter exploratory study -NADIM STUDYSLCG. J Clin Oncol 2018;36:abstr 8521. 